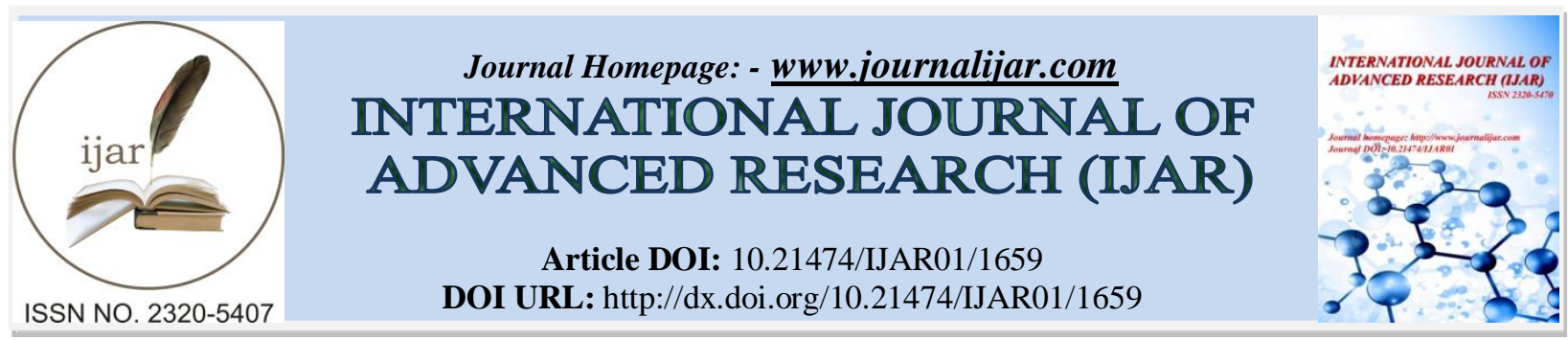

RESEARCH ARTICLE

\title{
SALT TOLERANCE AND BIOCHEMICAL CHARACTERIZATION OF RHIZOBIA ISOLATED FROM SOME WILD CROTALARIA SPP.
}

Kranti Balasaheb Patil and "Shivaji Sopanrao Kamble.

Mycology and Plant pathology laboratory, Department of Botany, Shivaji University, Kolhapur. 416004 MS (India).

\section{Manuscript Info}

Manuscript History

Received: 12 July 2016

Final Accepted: 23 August 2016

Published: September 2016

Key words:-

Crotalaria spp., Rhizobium, salt

tolerance, Saline, non saline.

\section{Abstract}

Thirty one isolates of Rhizobia isolated from root nodules of Crotalaria pallida Ait., Crotalaria verrucosa L. and Crotalaria retusa L. growing in coastal regions of Ratnagiri and Sindhudurg districts of Maharashtra showed $8 \%$ tolerance against $\mathrm{NaCl}$ (Sodium chloride). Physiological and biochemical characterization of these Rhizobium spp. were studied on non saline and modified saline YEMA medium. The aim of the experiments was to select salt tolerant Rhizobia which could be better perform in saline soil.

\section{Introduction:-}

Legume - Rhizobia symbiosis is well known to the world for its Nitrogen fixing mechanism. Rhizobia have considerable economic importance in agriculture as they play key role in Biological Nitrogen Fixation (BNF). Today agriculture faces a major problem of hypersalinity of soil. Some wild legumes and Rhizobia indigenous to coastal regions are likely to be adapted to salinity stress and prove themselves suitable for successful symbiosis in saline soils (Shishido and Pepper, 1990). Reclamation of this saline soils can achieved through the agencies of wild legume Rhizobial systems obtained from saline regions (Singleton et al., 1982). In the present investigation, 31 Rhizobium isolates were obtained from root nodules of different Crotalaria spp. viz. C. pallida Ait., C. verrucosa $\mathrm{L}$. and $C$. retusa $\mathrm{L}$. along the sea shore of Ratnagiri and Sindhudurga districts were screened for their salinity tolerance. Among them CPR-11, CVR-7 and CRR-4 showed maximum salt $(\mathrm{NaCl})$ tolerance up to $8 \%$. Rhizobium isolated from the nodules of Crotalaria spp. can be used to reclamate saline wastelands hence these salt tolerant Rhizobia further subjected to physiological and biochemical characterization.

\section{Material and Methods:-}

Collection of root nodules:-

Leguminous plants viz. Crotalaria pallida Ait., C. verrucosa L., C. retusa L. growing at sea coast of Ratnagiri $\left(16^{\circ}\right.$ $59^{\prime} 0^{\prime \prime}$ North, $73^{\circ} 18^{\prime} 0^{\prime \prime}$ East) and Sindhudurg (16 $4^{\prime} 0^{\prime \prime}$ North, $73^{\circ} 28^{\prime} 0^{\prime \prime}$ East) districts of Maharashtra were collected for the studies. Collection of root nodules was done by the method given by Somasegaran and Hoben (1985). The nodule status was studied by the method of Vincent (1970).

\section{Isolation of root nodulating bacteria}

The plant roots were washed under running tap water. The nodules were separated from the roots and washed with sterilized distilled water (SDW) for several times. Surface sterilization of nodules was carried out with $70 \%$ ethyl 
alcohol for 10 seconds and then with $0.1 \% \mathrm{HgCl}_{2}$ solution for 1 to 2 minutes. Surface sterilized root nodules were crushed in sterilized distilled water. Following Serial dilution, bacterial suspension was streaked onto Cango Red Yeast Extract Mannitol Agar (CRYEMA) plates and incubated at $28 \pm 2^{\circ} \mathrm{C}$ for 2 to 3 days (Vincent, 1970). Rhizobial colonies were picked up and sub cultured on Yeast Extract Mannitol Agar (YEMA).

\section{Authentication of Rhizobia:-}

Authentication of Rhizobia was done by Cango Red absorption test (Vincent, 1970); Glucose peptone agar (GPA) test (Vincent, 1970); Hofer's alkaline medium test (Hofer, 1935) and Ketolactose test (Bernaerts and De Ley, 1963).

\section{Cultural characters, staining and morphology:-}

The cultural characters such as colony shape, colony size, elevation, pigmentation, margin, opacity, mucocity etc. were studied by using standard Microbiology protocols. Bacterial cultures were examined for Gram staining reaction by the method of Hucker and Conn, (1923) using 48 hrs. old cultures. Bacterium shape was observed under the microscope. Cell size was measured by using ocular and stage micrometer as well as photographic methods.

\section{Salt tolerance in Rhizobia:-}

Sensitivity of Rhizobia to various salt $(\mathrm{NaCl})$ concentrations was done on YEMA plates as well as in YEM broth. All the strains were inoculated in test tubes containing YEM broth with different concentrations of salts i.e. Sodium Chloride $(1 \%, 1.5 \%, 2 \%, 2.5 \%, 3 \%, 3.5 \%, 4 \%, 4.5 \%, 5 \%, 5.5 \%, 6 \%, 6.5 \%, 7 \%, 7.5 \%, 8 \%, 8.5 \%, 9 \%, 9.5 \%$ and $10 \%$ ). Broth without $\mathrm{NaCl}$ served as 'Control'. The bacterial growth was recorded by using spectrophotometer (Shimadzu UV-1800) at $600 \mathrm{~nm}$ after $48 \mathrm{hr}$. incubation period at $28 \pm 2{ }^{\circ} \mathrm{C}$. YEMA plates supplemented with 1 to $10 \% \mathrm{NaCl}$ were streaked out with isolates in triplicate. Plates were incubated at $28 \pm 2^{\circ} \mathrm{C}$ for 48 hours. The isolates which were highly tolerant to salinity were further subjected to physiological and biochemical characterization.

\section{Biochemical and Physiological characterization of Rhizobium:-}

Biochemical and Physiological tests such as reactions in YEMA Graham and Parker (1964), Reaction in litmus milk (Skerman, 1967), Amylase activity (Starch hydrolysis) (De Oliverira, 2007), Catalase Test (Graham and Parker, 1964), Gelatin Hydrolysis (Difco and BBL Manual, 2009), Nitrate reductase, Oxidase Test Kovasks, (1956), Lipid hydrolysis, Citrate utilization (Koser, 1923), Hydrogen sulfide $\left(\mathrm{H}_{2} \mathrm{~S}\right)$ production (Hunter and Cercelius, 1938), Methyl Red and Vegos Proskauer test (Voges and Proskauer, 1898), Crystal violet sensitivity were carried out with respective methods.

\section{Carbohydrate nutrition:-}

The test was carried out on 'non saline' and modified 'saline' Basal medium (Bishop et. al 1976). Different carbohydrates (galactose, glucose, sucrose, dextrose, fructose, maltose, lactose, mannitol and raffinose) were substituted for Mannitol. Every carbohydrate source was added at $1.0 \%$ (wt/vol) concentration. Bacterial growth on YEMA slants was removed with cotton swabs and suspended in sterile distilled water to a density $10^{-7}$ per ml. 10 fold diluted cell suspension was added to the wells of a inoculators plate and incubated on to the surface of carbohydrate contained plates. Bishop's agar plate without carbohydrate was served as 'control' the agar plates were incubated for a week at $28^{0} \mathrm{C}$.

\section{Amino acid nutrition:-}

To determine utilization of nitrogen, different amino acids such as Amino- $\mathrm{N}$ - butyric acid, alanine, aspergin, glycine, histidine, lysine, serine, tyrosine and valine were incorporated in non saline and saline YEM broth at $0.01 \%$ concentration. $0.1 \mu \mathrm{l}$ bacterial cultures were added to each test tube. Broth without Yeast extract served as control. The bacterial growth was recorded by using (Shimadzu UV-1800) Spectrophotometer at 600nm after $48 \mathrm{hr}$. incubation period at $28 \pm 2^{0} \mathrm{C}$.

\section{Results :-}

Authentication test:-

All strains inoculated on saline and non saline YEMA amended with Cango red were remained creamy. No strain absorbed Cango red. All strains were failed to grow on GPA medium. Rhizobial strains inoculated on Hofer's alkaline medium were unable to grow at high $\mathrm{pH}$ (11.00). Isolates were unable to produce 3 - Ketolactase because no yellow ring was observed around the colony when flooded with Benedict's reagent on Lactose Agar medium.

\section{Cultural characters, staining and morphology:-}


Colony characters: All isolates were observed for cultural characteristics on saline and non saline YEMA after 48 hrs incubation at $28^{\circ} \mathrm{C}$. Colonies of all isolates on both the media were circular in shape and creamy in colour. All isolates on both media showed convex elevation, entire margins, mucoid consistency and opaque nature. Comparatively smaller colonies ( 1 to $3 \mathrm{~mm}$ diameter) were observed on saline YEMA while on non saline medium colonies ranged 2 to $6.5 \mathrm{~mm}$ in diameter. From above observations it was clear that these were fast growing Rhizobia.

\section{Cell characteristics:-}

All isolates were gram negative, rod shaped and non spore forming bacteria. The cell size ranged 0.5 to $1 \mathrm{X} 1.5$ to $2.9 \mu \mathrm{m}$ on non saline medium while 0.7 to $1.2 \mathrm{X} 1.7$ to $2.9 \mu \mathrm{m}$ on saline medium.

\section{Salt tolerance:-}

Sensitivity of these 31 isolates to $\mathrm{NaCl}$ ranged from 1 to $8 \%$. Among the 31 isolates 3 isolates were resistant to $8 \%$ concentration of $\mathrm{NaCl}$. From Table No. 1., CPR-11, CVR-7 and CRR-4 isolate having maximum (8\%) tolerance to $\mathrm{NaCl}$. From Fig. No. 1 to 3, It is clear that, Isolate CPR-11, CVR-7 and CRR-4 grew highest at concentration 2 to $3 \% \mathrm{C}$. growth was decreased slowly towards $8 \% \mathrm{NaCl}$. Beyond this they showed very poor or no growth at $9 \%$ $\mathrm{NaCl}$. All isolates showed significant growth at $8 \% \mathrm{NaCl}$.

\section{Biochemical and physiological characterization:-}

Reaction in YEMA: saline and non saline YEMA plates containing Bromothymol blue (BTB) were inoculated with Rhizobium impregnated paper disc showed yellow coloured zone around the disc. It indicated change in the $\mathrm{pH}$ of the medium was due to acid producers i. e. Fast growing Rhizobium. All isolates were acid producers and not affected by salinity. Reaction in Litmus Milk: Isolates CPR-11, CVR-7 and CRR-4 showed acidic reaction in saline and non saline litmus milk medium. Amylase activity: A clear halos in the midst of the dark plate was observed in isolate CRR-4 in both saline and non saline starch agar when iodine reagent is applied. Catalase test: All isolates showed positive Catalase activity. Air bubbles produced on the glass slide when $\mathrm{H}_{2} \mathrm{O}_{2}$ added to the smear of bacteria. Gelatinase activity: All isolates from saline and non saline nutrient gelatin medium showed liquefaction of gelatin. Nitrate reductase activity: All isolates from saline and non saline medium were reduced Nitrate. Oxidase activity: All isolates from saline and non saline medium showed positive results for oxidase test. Lipid hydrolysis: All isolates in both saline and non saline medium showed a clear halo surrounding the bacterial growth identifies the presence of lipase. Lipase production was not affected by salinity. Citrate Utilization: All isolates were grown on non saline Simmon's citrate agar medium and gave positive test by changing colour from green to blue. Isolates from saline medium remained green due to trace or no growth of Rhizobium isolate. $\mathbf{H}_{2} \mathbf{S}$ production: No black precipitation was observed on Triple Sugar Iron (TSI) medium. Isolates produced gas only. Better results were found on non saline medium than saline medium. Indole test: Bacteria were unable to degrade tryptophan (amino acid). All isolates from modified saline and non saline Tryptophan broth showed negative Indole test. Methyl Red and Vogas Proskaure test (MR-VP): Both tests on saline and non saline MR-VP (Glucose Phosphate broth) were found negative. Physiological and Biochemical characteristics of Rhizobia are given in Table No. 2.

\section{Crystal violet sensitivity:-}

All isolates from saline and non saline media were sensitive to crystal violet having 1:1000; 1: 10000 and 1:50000 concentrations. CPR-11 and CVR-7 from both saline and non saline media grown on 1:100000 concentrations. While CRR-4 was unable to grow on both media at 1:100000 concentrations. All isolates from both the media tolerated 1:200000 concentrations. From, Table No. 3, it is proved that fast growing Rhizobia were less sensitive to high concentrations of Crystal violet .

\section{Carbohydrate nutrition:-}

Sugars like sucrose, galactose, fructose, ribose, raffinose, maltose, xylose and mannitol were utilized by all isolates from Bishop's media. CPR-11, CVR-7 and CRR-4 from non saline media utilized all carbohydrates except rhamnose. CPR-11 from saline medium was unable to utilize sorbitol. Arabinose from saline YEM broth was not utilized by CPR-11, CVR-7 and CRR-4. (Table No. 4). 


\section{Amino acid nutrition:-}

Amino acids such as amino- $\mathrm{N}$ - butyric acid, alanine, aspergin, histidine, lysine, serine and tyrosine were utilized by all rhizobial isolates from both saline and non saline medium. Glycine and valine were not utilized by all rhizobial isolates. (Table No. 5).

\section{Discussion:-}

Results of authentication tests proved that all isolates were Rhizobium and different from Agrobacterium or other bacteria. Colonies obtained from non saline and modified saline media were circular, convex, opaque, mucoid with entire margin. The results were in agreement with Gauri et al., (2011). Comparatively smaller colonies were observed on saline medium. According to Steinborn and Roughly, (1975) and Singleton et al., (1982) salinity increases the generation time of Rhizobia, which results in formation of smaller colonies on saline YEMA. All isolates from non saline and modified saline media were gram negative, rod shaped and non spore forming. The results are similar with Sadowsky et al., (1983). There was a slight variation in size of cell under stressed condition. Rhizobia respond to stress by changing their size and morphology.

It was observed that, sensitivity of these 31 isolates to $\mathrm{NaCl}$ ranged from 1 to $10 \% \mathrm{NaCl}$. Among the 31 isolates six isolates were resistant to $8 \%$ concentration of $\mathrm{NaCl}$. There are many workers who have also recorded sensitivity of Rhizobia to various concentrations of $\mathrm{NaCl}$. According to Kucuk et al., (2006) Rhizobium isolated from root nodules of Phaseolus vulgaris tolerated 5\% NaCl. Sharma et al., (2013) reported that Rhizobia isolated from root nodules of Sesbania sesban, Lablab purpureus and Cajanus cajan shown growth on medium containing $40 \mathrm{dsm}^{-1}$ of $\mathrm{NaCl}$. According to Mandal, (2014) out of 27 strains of Rhizobium trifolli isolated from root nodules of Trifolium alexandrinum tolerated 3\% concentration of $\mathrm{NaCl}$. Ali et al., (2009) reported that Rhizobia isolated from Leucaena leucocephala, Tephrosia purpurea and Crotalaria medicagina tolerated 4.5\% concentration of NaCl. Bajekal (1996) found that, out of 16 strains of halotolerant rhizobia, two tolerated 3.5\% salt, one strain 4.5, two strains, 5.0, four strains, 5.5, two strains, 6.0, three strains, 6.5 and two strains tolerated up to $7.0 \% \mathrm{NaCl}$. Rhizobium is more tolerant to salts than their host legume; hence survive in saline condition (Subha Rao et al., 1972 and 1974). El- Mokadem et al., (1991) concluded that, salt tolerant Rhizobia can improve yield of legumes under salt condition. Hashem et al., (1998); Shamseldin and Werner, (2005) found that, legume plants grew and survived well in saline condition when they were inoculated with salt tolerant Rhizobia. According to Mandal, (2014) salt tolerant strains of Rhizobium trifolli can be useful under stress condition.

On the basis of biochemical tests; isolate showed acidic to strongly acidic reaction in litmus milk like the previous results of Sadowsky et al., (1983). A yellow ring or colouration around the culture disc on YEMA amended with Bromothymol blue indicated isolates were acid producing or fast growing root nodulating bacteria Rhizobia. The results were in close agreement with Norris (1965). Positive tests were found for Catalase, gelatinase, oxidase and nitrate reductase from non saline and saline condition. A lipid hydrolysis test was also found positive. These results were similar with Sadowsky et al., (1983) and Deshwal and Chaubey, (2014). According to De oliveria et al., (2007) Rhizobium utilized starch from different sources. Most of the Rhizobia were unable to produce enzyme gelatinase. Hunter et al., (2007) observed negative gelatinase activity. According to Sadowsky et al., (1983) fast growing Rhizobia isolated from soybean root nodules could produce enzyme gelatinase but slow growers were unable to produce gelatinase. These tests were not affected by salinity. All isolates utilized citrate from non saline medium but were unable to utilize from modified Simmon's Citrate Agar. According to Gauri et al., (2011) all isolates of $R$. trifolii were unable to utilize citrate. Isolates found negative for Methyl Red (MR), Voges Proskauer (VP) and Indole tests. These findings were closely in agreement with Shahazad et al., (2012) characterized Rhizobium strain from root nodules of Alfalfa. From the above observations these Rhizobia were fast growing Rhizobia which are more salt tolerant.

\section{Conclusion:-}

Efforts were carried out to develop salt tolerant Rhizobia. The fast growing strains of Rhizobium are alkali tolerant. Rhizobia are more tolerant to alkalinity than their legume host. Hence these Rhizobia improve the alkali tolerance of legumes and become helpful in the amelioration of alkaline soil.

\section{Acknowledgement:-}

Authors are thankful to UGC, New Delhi for awarding BSR fellowship for the Research. 
Table No. 1:- Sensitivity of Rhizobium isolates to $\mathrm{NaCl}(\%)$ in vitro.

\begin{tabular}{|c|c|c|c|c|c|c|c|c|c|c|c|c|c|c|c|c|c|c|c|c|}
\hline \multirow{2}{*}{ Sr. No } & \multirow{2}{*}{$\begin{array}{l}\text { Rhizobium } \\
\text { isolates }\end{array}$} & \multicolumn{19}{|c|}{ Concentration of $\mathrm{NaCl}$ in $\%$} \\
\hline & & 1 & 1.5 & 2 & 2.5 & $\boldsymbol{\beta}$ & 3.5 & 4 & 4.5 & 5 & 5.5 & 6 & 6.5 & 7 & 7.5 & 8 & 8.5 & 9 & 9.5 & 10 \\
\hline 1. & CPR-1 & + & + & + & + & + & + & + & + & 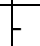 & F & 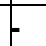 & - & - & - & $F$ & - & - & 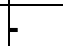 & - \\
\hline 2. & CPR-2 & + & + & + & + & + & + & + & + & + & + & + & - & - & + & 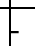 & + & - & + & - \\
\hline 3. & CPR-3 & + & + & + & + & + & + & + & + & + & F & f & - & - & 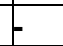 & - & - & - & 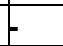 & \\
\hline 4. & CPR-4 & + & + & + & + & + & + & + & + & + & + & 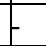 & - & 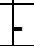 & - & $F$ & 5 & - & 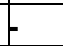 & \\
\hline 5. & CPR-5 & + & + & + & + & + & + & + & + & + & F & 5 & - & - & 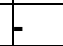 & - & 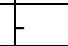 & - & 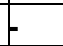 & 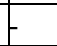 \\
\hline 6. & CPR-6 & + & + & + & + & + & + & + & + & + & f & 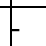 & - & - & + & t & 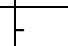 & - & 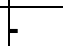 & 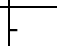 \\
\hline 7. & CPR-7 & + & + & + & + & - & - & 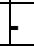 & 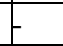 & - & 5 & 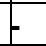 & - & - & 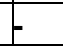 & - & 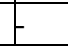 & - & 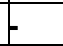 & - \\
\hline 8. & CPR-8 & + & + & + & + & + & + & + & + & + & + & F & F & 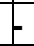 & F & - & 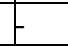 & - & 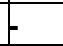 & 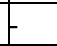 \\
\hline 9. & CPR-9 & + & + & + & + & + & - & - & 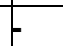 & - & 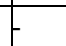 & $f$ & - & - & 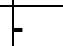 & - & 5 & - & 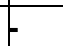 & 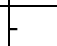 \\
\hline 10 & CPR-10 & + & + & + & + & + & + & + & + & + & + & + & - & - & 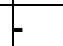 & - & 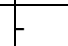 & - & 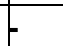 & 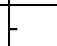 \\
\hline 11 & CPR-11 & + & + & + & + & + & + & + & + & + & + & + & + & + & + & + & $F$ & - & 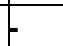 & 5 \\
\hline 12 & CPR-12 & + & + & + & + & + & + & + & + & + & F & F & 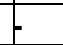 & - & - & $F$ & $F$ & - & 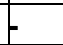 & $F$ \\
\hline 13 & CPR-13 & + & + & + & + & + & + & + & + & + & 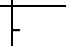 & - & 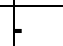 & - & - & - & 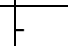 & - & 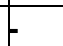 & - \\
\hline 14 & 4 CPR-14 & + & + & + & + & + & + & + & + & + & + & + & + & - & F & $F$ & 5 & - & F & 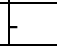 \\
\hline 15 & CVR-1 & + & + & + & + & + & + & + & + & + & 5 & 5 & - & - & F & 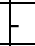 & 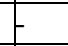 & - & 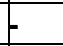 & 5 \\
\hline 16 & CVR-2 & + & + & + & + & + & + & + & + & - & 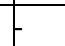 & 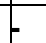 & - & - & - & - & 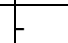 & - & 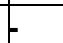 & - \\
\hline 17 & CVR-3 & + & + & + & + & + & + & + & + & + & + & f & - & 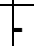 & - & $F$ & $F$ & - & 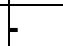 & 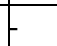 \\
\hline 18 & CVR-4 & + & + & + & + & + & + & - & 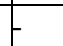 & 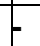 & - & f & - & 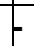 & - & $F$ & $F$ & - & 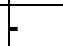 & 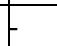 \\
\hline 19 & CVR-5 & + & + & + & + & + & + & + & + & + & 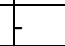 & - & 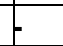 & - & - & - & 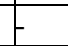 & - & 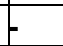 & - \\
\hline 20 & CVR-6 & + & + & + & + & + & + & + & + & + & + & + & + & + & - & - & 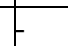 & - & 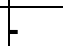 & + \\
\hline 21 & CVR-7 & + & + & + & + & + & + & + & + & + & + & + & + & + & + & + & - & - & 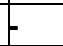 & 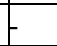 \\
\hline 22 & CVR-8 & + & + & + & + & + & + & + & + & + & + & + & - & - & 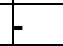 & 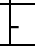 & 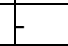 & - & 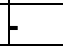 & 5 \\
\hline 23 & CVR-9 & + & + & + & + & + & + & + & + & + & + & + & - & - & 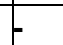 & 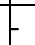 & 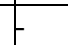 & - & 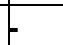 & 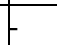 \\
\hline 24 & CVR-10 & + & + & + & + & + & + & + & + & + & + & 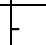 & - & - & 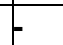 & - & 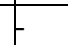 & - & 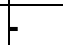 & 6 \\
\hline 25 & CRR-1 & + & + & + & + & + & + & + & + & + & - & 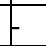 & - & - & 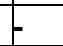 & 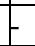 & - & - & 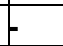 & 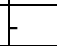 \\
\hline 26 & CRR-2 & + & + & + & + & + & + & + & + & + & + & + & - & - & 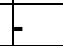 & 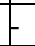 & 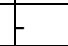 & - & 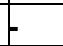 & - \\
\hline 27 & CRR-3 & + & + & + & + & + & + & + & + & + & + & + & - & - & + & - & 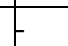 & - & + & - \\
\hline 28 & CRR-4 & + & + & + & + & + & + & + & + & + & + & + & + & + & + & + & 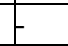 & - & 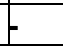 & - \\
\hline 29 & CRR-5 & + & + & + & + & + & + & + & + & + & + & 5 & F & 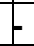 & F & - & 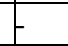 & - & F & 5 \\
\hline 30 & CRR-6 & + & + & + & + & + & + & + & + & + & + & + & - & - & 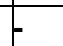 & - & $t$ & - & 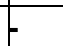 & 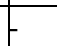 \\
\hline 31 & CRR-7 & + & + & + & + & + & + & + & + & + & + & - & - & - & 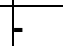 & & 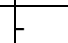 & - & & \\
\hline
\end{tabular}

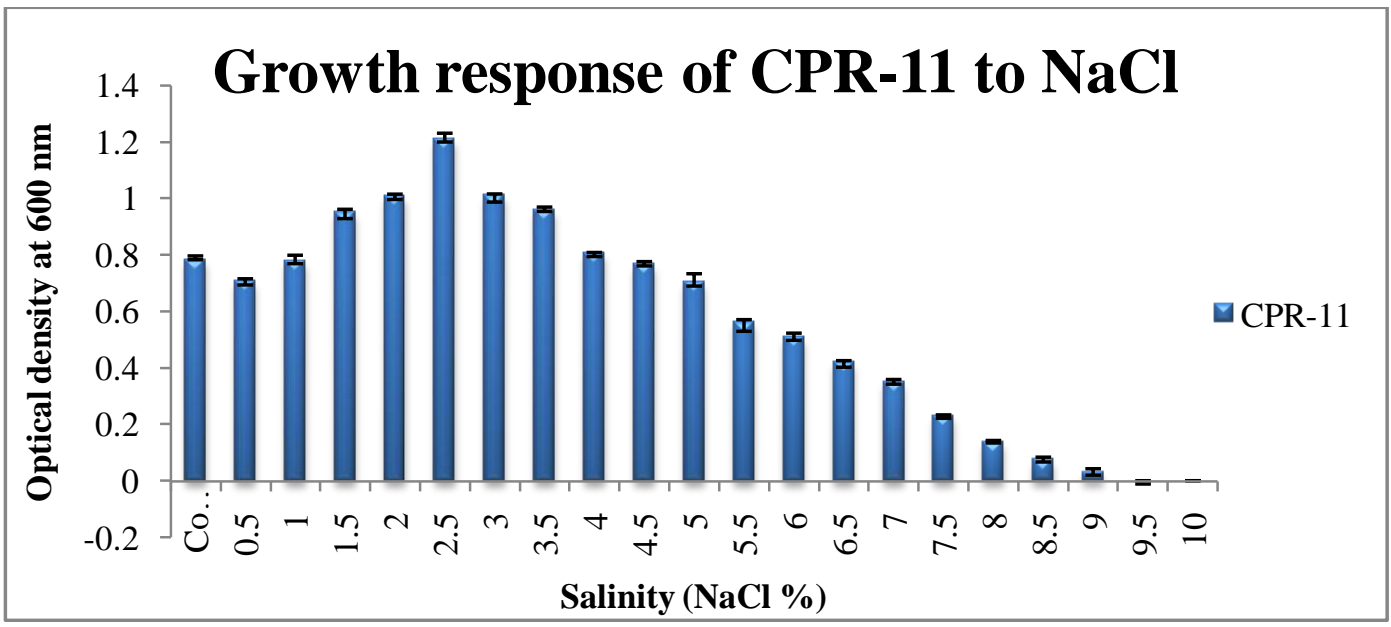

Fig.1:- Dose response curve of CPR-11 to various concentrations of $\mathrm{NaCl}$ on $\mathrm{YEM}$ broth 


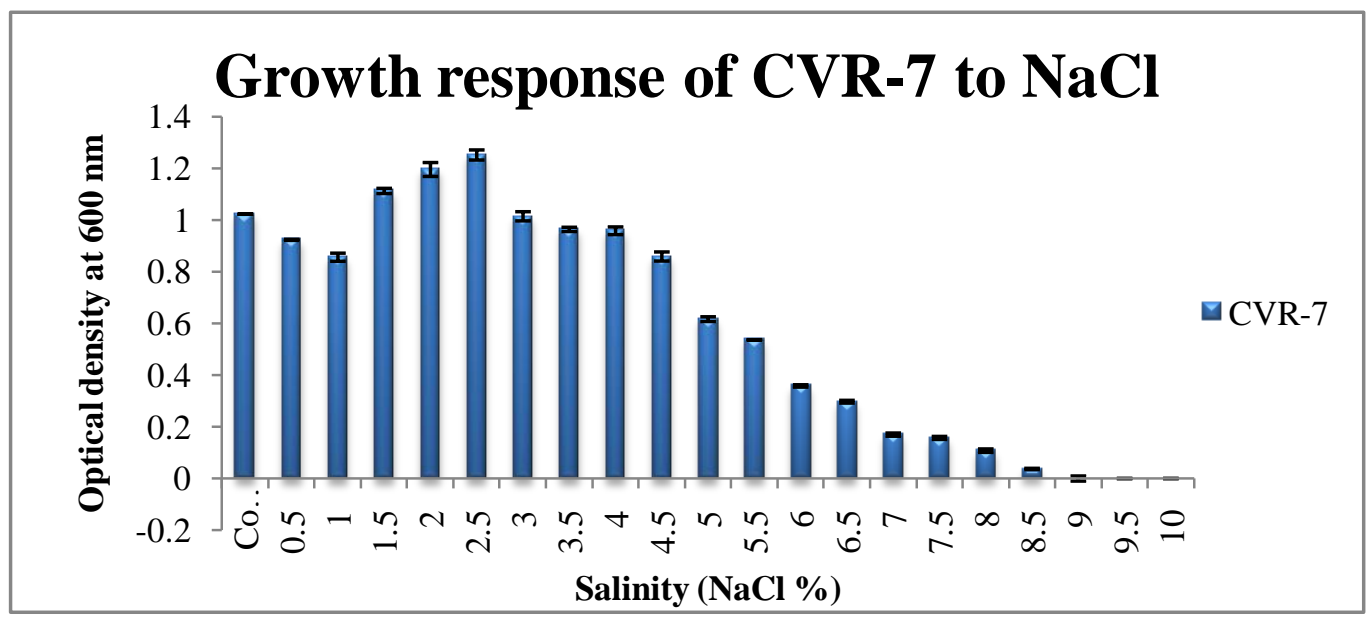

Fig. 2:- Dose response curve of CVR-7 to various concentrations of $\mathrm{NaCl}$ on YEM broth.

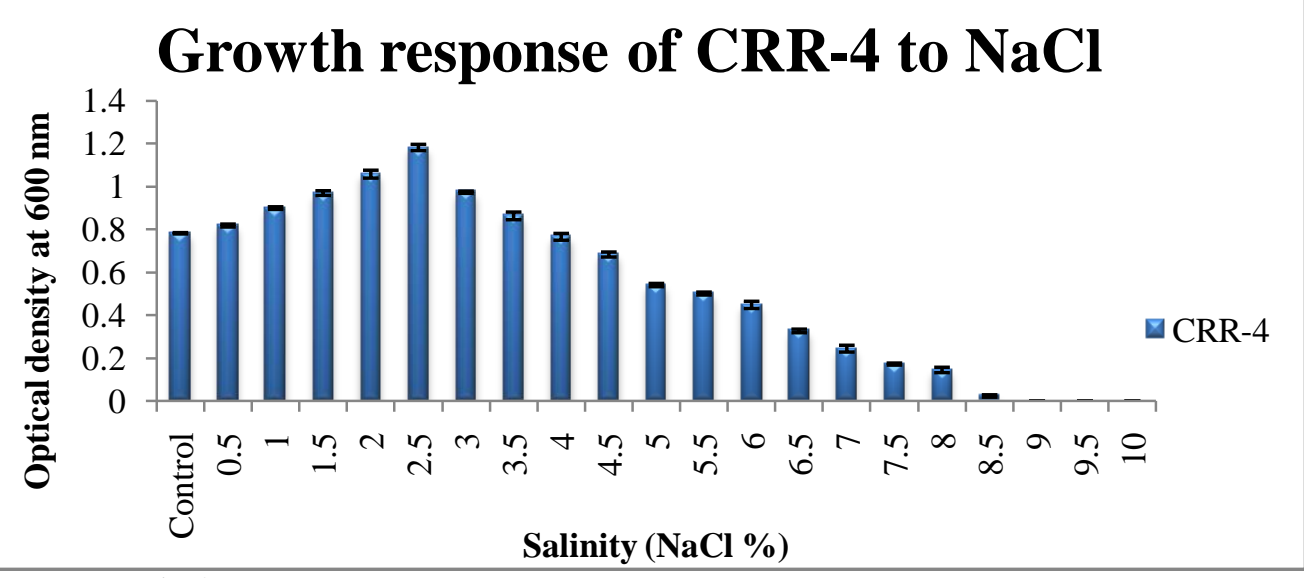

Fig.3:- Dose response curve of CRR-4 to various concentrations of $\mathrm{NaCl}$ on YEM broth.

Table No. 2:- Physiological and Biochemical characteristics of Rhizobia.

\begin{tabular}{|l|l|l|l|l|l|l|}
\hline \multirow{2}{*}{$\begin{array}{l}\text { Biochemical and } \\
\text { Physiological } \\
\text { characteristics }\end{array}$} & \multicolumn{2}{l}{ Rhizobium Isolates } & CVR-7 & \multicolumn{2}{l|}{ CRR-4 } \\
\cline { 2 - 7 } & CPR-11 & S & NS & S & NS & S \\
\cline { 2 - 7 } Reaction in YEMA & Ac & Ac & Ac & Ac & Ac & Ac \\
\hline $\begin{array}{l}\text { Reaction in Litmus } \\
\text { Milk }\end{array}$ & Ac & Ac & Ac & Ac & Ac & Ac \\
\hline Amylase & - & - & - & - & + & + \\
\hline Catalase & + & + & + & + & + & + \\
\hline Gelatinase & + & + & + & + & + & + \\
\hline Oxidase & + & + & + & + & + & + \\
\hline Nitrate reduction & + & + & + & + & + & + \\
\hline Lipid hydrolysis & + & + & + & + & + & + \\
\hline Citrate Utilization & + & - & + & - & + & - \\
\hline H2S production & - & - & - & - & - & - \\
\hline Methyl Red Test & - & - & - & - & - & - \\
\hline Vogas Proskaure test & - & - & - & - & - & - \\
\hline Indol & - & - & - & - & - & - \\
\hline
\end{tabular}
reaction 
Table No. 3:- Sensitivity of Rhizobia to the Crystal violet.

\begin{tabular}{|l|l|l|l|l|l|l|l|l|l|l|}
\hline \multirow{2}{*}{$\begin{array}{l}\text { Rhizobial } \\
\text { strain }\end{array}$} & \multicolumn{9}{|l|}{ Crystal violet concentration } \\
\cline { 2 - 12 } & $\mathbf{1 : 1 0 0 0}$ & $\mathbf{1 : 1 0 , 0 0 0}$ & $\mathbf{1 : 5 0 , 0 0 0}$ & $\mathbf{1 : 1 , 0 0 , 0 0 0}$ & \multicolumn{1}{|c|}{$\mathbf{2 , 0 0 , 0 0 0}$} \\
\cline { 2 - 11 } & NS & S & NS & S & NS & S & NS & S & NS & S \\
\hline CPR-11 & - & - & - & - & - & - & + & + & + & + \\
\hline CVR-7 & - & - & - & - & - & - & + & + & + & + \\
\hline CRR-4 & - & - & - & - & - & - & - & - & + & + \\
\hline
\end{tabular}

Table No. 4:- Effect of various Carbohydrate sources on the growth of Rhizobial isolate on Basal medium.

\begin{tabular}{|c|c|c|c|c|c|c|}
\hline \multirow{3}{*}{$\begin{array}{l}\text { Sugar } \\
1.0 \%\end{array}$} & \multicolumn{6}{|c|}{ Rhizobial isolate } \\
\hline & \multicolumn{2}{|c|}{ CPR-11 } & \multicolumn{2}{|c|}{ CVR-7 } & \multicolumn{2}{|c|}{ CRR-4 } \\
\hline & NS & $\mathbf{S}$ & NS & $\mathbf{S}$ & NS & $\mathbf{S}$ \\
\hline Sucrose & + & + & + & + & + & + \\
\hline Sorbitol & + & - & + & + & + & + \\
\hline Glucose & + & + & + & + & + & + \\
\hline Galactose & + & + & + & + & + & + \\
\hline Fructose & + & + & + & + & + & + \\
\hline Ribose & + & + & + & + & + & 9+ \\
\hline Raffinose & + & + & + & + & + & + \\
\hline Rhamnose & - & - & - & - & - & - \\
\hline Maltose & + & + & + & + & + & + \\
\hline Xylose & + & + & + & + & + & + \\
\hline Arabinose & + & - & + & - & + & - \\
\hline Mannitol & + & + & + & + & + & + \\
\hline
\end{tabular}

NS =Non saline medium, $\mathbf{S}=$ Saline medium, + =Bacterial growth, - =No bacterial growth

Table No. 5:- Effect of various amino acids on the growth of Rhizobial isolate in YEM broth.

\begin{tabular}{|c|c|c|c|c|c|c|}
\hline \multirow[t]{3}{*}{ Amino acid $0.01 \%$} & \multicolumn{6}{|c|}{ Rhizobial isolates } \\
\hline & \multicolumn{2}{|c|}{ CPR-11 } & \multicolumn{2}{|c|}{ CVR-7 } & \multicolumn{2}{|c|}{ CRR-4 } \\
\hline & $\mathbf{N S}$ & $\mathbf{S}$ & $\mathbf{N S}$ & $\mathbf{S}$ & $\mathbf{N S}$ & $\mathbf{S}$ \\
\hline Amino- N- butyric acid & + & + & + & + & + & + \\
\hline Alanine & + & + & + & + & + & + \\
\hline Aspergin & + & + & + & + & + & + \\
\hline Glycine & - & - & - & - & - & - \\
\hline Histidine & + & + & + & + & + & + \\
\hline Serine & + & + & + & + & + & + \\
\hline Tyrosine & + & + & + & + & + & + \\
\hline Valine & - & - & - & - & - & - \\
\hline
\end{tabular}

NS =Non saline medium, $\mathbf{S}=$ Saline medium, + =Bacterial growth, - = No bacterial growth

\section{References:-}

1. Ali, S. F., Rawat L. S., Meghavanshi, M. K. and Mahna, S. K. (2009): Selection of stress- tolerant Rhizobial isolates of wild legume growing in dry regions of Rajasthan, India. ARPN J. Agric Biol. Sci., 4:13-18.

2. Bajekal, S. S. (1996): Studies on salt tolerant root nodule bacteria from wild legumes growing along the Ratnagiri sea coast. Thesis submitted to Shivaji University Kolhapur, India.

3. Bernaerts, M. J. and De Ley, J. (1963): A biochemical test for crown gall bacteria. Nature, 197: $406-407$.

4. Bishop, P. E., Guevara, J. G., Engelke, J. A. and Evans, H. J. (1976): Relation between glutamine synthetase and nitrogenase activites in the symbiotic association between Rhizobium japonicum and Glycine max. Plant Physiol. 57:542-546.

5. De Oliverira A. N., De Oliverira L. A., Andrade, J.S. Chagas, J.A.F. (2007): Rhizobia amylase production using various starchy substances as carbon substrates. Braz. J. Microbiol. 38:208-216.

6. Deshwal, V. K. and Chaubey, A. (2014): Isolation and characterization of Rhizobium leguminosarum from root nodule of Pisum sativum. J. Acad. Ind. Res., 3(8): 464-467. 
7. Difco and BBL Manual. (2009): Manual of Microbiological Culture Media, $2^{\text {nd }}$ edition. Becton, Dickinson and Company, Maryland, USA., 402-403.

8. El- Mokadem, M. T., Helemish, F. A. and Abdel Wahab, S. M. (1991): Salt responce of clover and alfalfa with salt tolerant strains of Rhizobium. Ain. Shams. Sci. Bull., 28 B: 441-468.

9. Gauri, Singh, A. K., Bhatt, R. P., Pant, S. Bedi, M. And Naglot, A. (2011): Characterization of Rhizobium isolated from root nodules of Trifolium alexandrinum. journal of Agricultural technology., 7(6): 1705-1723.

10. Graham, P. H. and C. A. Parker, (1964): Diagnostic features in the characterization of the root nodule bacteria of legumes. Plant and soil., 20:383-395.

11. Hashem F. M., Swelim D. M., Kuykendall L. D., Mohamed A. I., Abdel wahab S. M. and Hegazi N. I. (1998): Identification and Characterization of salt and thermotolerant Leucaena nodulating Rhizobium strains. Biology and fertility of Soils., 27:335-341.

12. Hofer, H. W. (1935): Methods for distinguishing between legume bacteria and there most common contaminants. J. Am. Soc. Agron., 27:228-230.

13. Hucker, G. J. and Conn, H. J. (1923): Method of Gram staining. N Y State Agric. Exp. Stn. Tech. Bull. 93:3-37.

14. Hunter, C. A. and Cercelius, H. G. (1938): Detection in Hydrogen sulphide in cultures. J. Bacteriol. 35:185-196.

15. Hunter, W. J., Kuykendall, L. D. and Manter, D. K. (2007): Rhizobium selenireducens sp. Nov.: a selenite reducing proteobacteria isolated from a bioreactor. Curr. Microbiol. 55:455-460.

16. Koser, S. A., (1923): Utilization of the salts of organic acids by the colon- aerogenes group. J. Bact., 8:493-520.

17. Kovasks, N. (1956): Identification of Pseudomonas pyocyanea by the oxidase reaction. Nature, (London) 178:703.

18. Kucuk, C., Kivanc, M. and Kinaci, E. (2006): Characterization of Rhizobium sp. Isolated from Bean. Turk J. Biol., 30:127-132.

19. Mandal, H. K. (2014): Isolation of salt tolerant strains of R. trifolli. Int. J. Agric. Food. Sci. Tech., 5(4): 325332.

20. Norris, D. O. (1965): Acid production by Rhizobium: a unifying concept. Plant Soil., 22:143-166.

21. Sadowsky, M. J. Keyser, H. H. And Bohlool, B. B. (1983): Biochemical characterization of fast and slow growing Rhizobia that nodulate Soybeans. Int. J. Sys. Bacteriol., 33 (4): 716-722.

22. Shahazad, F., Shafee, M., Abbas, F., Babar, S., Tariq, M. M. And Ahamed, Z., (2012): Isolation and biochemical characterization of Rhizobium melilotii from root nodules of Alfalfa (Medicago sativa). J. Anim. Plant Sci., 22 (2): 522-524.

23. Shamseldin, A. and Werner, D. (2005): High salt and high $\mathrm{P}^{\mathrm{H}}$ tolerance of new isolated Rhizobium etli strains from Egyptian soils. Current Microbiologia., 50:11-16.

24. Sharma, S. R., Rao, N. K., Gokhale, T. S and Ismile, S. (2013): Isolation and characterization of salt tolerant rhizobia native to the desert soils of United Arab Emirates. Emir. J. Food. Agric., 25 (2): 102-108.

25. Shishido, M. and Pepper, I. L. (1990): Identification of dominant indigenous Rhizobium meliloti by plasmid profiles and intrinsic antibiotic resistance. Soil Biol. Biochem., 22(1):11-16.

26. Singleton, P. W., El Swaiify, S. A., Bohlool, B. B. (1982): Effect of salinity on Rhizobium growth and survival. Applied and Environmental Microbiology., 44: 884-890.

27. Skerman, V. B. D. (1967): A guide to the identification of the genera of bacteria. The Williams and Wilkins Co. Baltimore.

28. Somasegaran, P. and Hoben, H. J. (1985): Methods in Legume- Rhizobium Technology. University of Hawaii, Nif Tal Project, Paia, Hawaii.

29. Steinborn, J., and Roughly, R. J. (1975): Toxicity of Sodium chloride ions to Rhizobium spp. in broth and peat culture. J. Appl. Bacteriol., 39:133-138.

30. Subba Rao, N. S., Lakshmi kumari, M., Singh, C. S., and Magu, S. P. (1972): Nodulation of Lucerne (Medicago sativa L.) under the influence of sodium chloride. Indian J. Agric. Res., 42: 386-388.

31. Subba Rao, N. S., Lakshmi kumari, M., Singh, C. S., and Biswas, A. (1974): Salinity and alkalinity in relation to legume- Rhizobium symbiosis. Proc. INSA, 40: 544-547.

32. Vincent, J. M. (1970): A manual for the practical study of the root- nodule bacteria. I. B. P. handbook no. 15. Blackwell scientific publications, Oxford. 15:164.

33. Voges, O. And Proskauer B. (1898): Z. Hyg. Infektionskr., 28:20. 